\title{
Music Scoring for Film Using Fruity Loops Studio
}

\author{
Arsya Febrian $^{1}$, Hestiasari Rante $^{1}$, Sritrusta Sukaridhoto ${ }^{1}$, and Akhmad Alimudin ${ }^{2}$ \\ ${ }^{1}$ Department of Creative Multimedia Technology, Politeknik Elektronika Negeri Surabaya, \\ Jl. Raya ITS-Sukolilo, Surabaya, East Java, 60111 Indonesia \\ ${ }^{2}$ Department of Computer Science and Engineering, Toyohashi University of Technology, \\ Tempaku, Toyohashi 441-8580, Japan
}

\begin{abstract}
Making music for a film can be said to be quite challenging for some people with the necessity that music can evoke the atmosphere in the film. Determination and placement of audio aspects into visual form are things done in the music scoring process. Of course, it will be very inconvenient and inefficient when making music must be through recording instruments manually through the studio. As technology develops in the world of music production, making music for films can now be made using only a computer. This can happen thanks to the Digital Audio Workstation (DAW) software. Nowadays, various types of DAW are emerging, including one that is quite well known, Fruity Loops Studio or commonly called FL Studio. This study aims to find out how the music scoring process for a film using FL Studio, as a reference for making music for films.
\end{abstract}

Keywords: Digital audio workstation, instrument, music for film, music production, soundtrack.

\section{Introduction}

Determination and placement of audio aspects into visual form are things done in the music scoring process [1]. Scores are original music written specifically for individual films. Sometimes called soundtracks, movie scores can be extremely recognizable. A powerful score can help to inspire the audience's feelings [2]. It is not the same as making a soundtrack because it tends to have more dynamics. It conveys emotions, moods and characters in a way that dialogue cannot do in film [3].

According to Roger Manuel, the silent film era was a time when background music was the only sound in a film for various reasons. Music in films was a noise reduction for a film projector when the film was playing, it also as a legacy of theatrical traditions of the past [4]. Most musical accompaniments were live piano; and later, full orchestras shouldered the musical burden. With this initial linkage of music and moving pictures in mind, it can be said that the aesthetic conjunction of music and film was due to be made, to the benefit of both artistic expressions and to enhance the perceptual impression [5].

As time goes by, music used in films now not only uses direct instruments, but also uses instruments made by computers. Music producers now use software to make their music arrangements more alluring. This software can be implemented on a computer to allow an artist to write, record, edit, and mix their music. The software is known as a digital audio workstation (DAW) [6]. 
There are several popular DAW software used by musicians, including several film composers. One of the most popular DAWs today is Fruity Loops Studio or commonly called FL Studio. There are several reasons why FL Studio is used in this research; it provides quite complete features, ease of use, and the value of the latest version FL Studio 20 as a DAW software [7].

In terms of features, FL studio 20 can use the latest type of plugin, VST3, where most other DAWs cannot use this type of plugin. Besides that, FL Studio 20 also has its sound driver called ASIO4all. This ASIO driver is very powerful and compatible with various types of additional hardware such as audio interfaces and midi controllers used in making music. According to ancient DAW users, FL Studio 20 still seems very stiff. However, this has become an advantage for beginner music producers, because FL Studio 20's organized workflow makes it easier to understand. In the help window, a description of all buttons, knobs, and switches directed by the mouse pointer can be found. Besides, FL Studio also has the oldest and largest forum to help anyone who has difficulty in making music.

Finally, regarding fees from FL Studio 20, different from most DAWs which currently use a monthly to per year subscription system, FL Studio 20 is only purchased at the beginning without the need of subscription. Image-Line Corporation also guarantees its users to get life-time free updates.

\section{Related works}

Bilqis Firdausiyah conducted a study entitled Music Composing and Scoring for 3D Short Movie. The study found that most of the expert reviewers in their fields prohibit 'jumping' between instruments in a film's music, audio in $3 \mathrm{D}$ movie must be appropriate with the visual that shown, also there should be no noise in the music presented. Suliza [8] conducted a study entitled Experimental Study on the Effects of Music of Movie Trailers. The study found that music familiarity cannot sufficiently influence consumers's intention to watch, instead music congruency of movie trailers can increase the intention to watch the movie. It strengthen the trailer's intended message so that consumers can be attracted and the intention to watch the movie becomes higher.

\section{Process}

\subsection{Music scoring}

The first thing to do in this process is to input each instrument that will be used and the visual of film into FL Studio, which will be used as a reference for the music score. Figure 1 below shows the way to input instruments in the channel rack; a section list that contains instruments, sounds and automation used in a track [9].

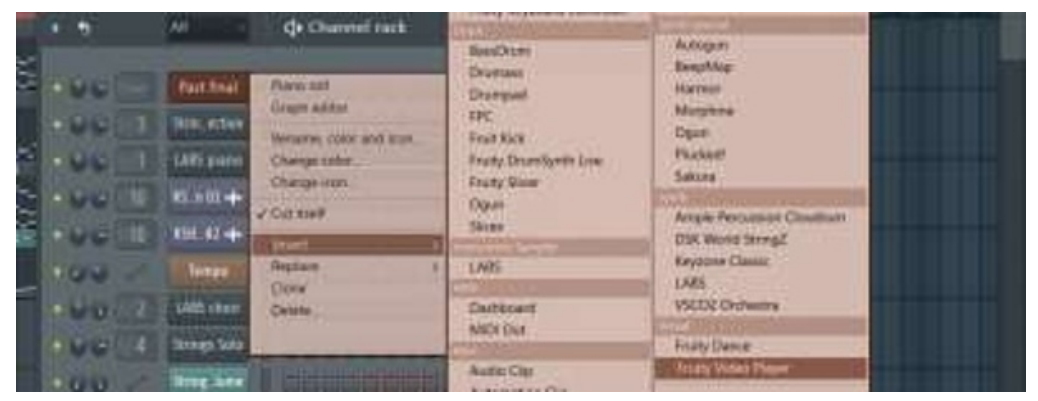

Fig. 1. Instruments input in channel rack. 
Figure 2 shows how a film is displayed in FL Studio after being included in the fruity video player. The film on the fruity video player can be set to run according to the time mark on the playlist by clicking on the green chain icon in the fruity video player as shown in the following Figure 2, so the film can go hand in hand with the music arranged in the playlist later.

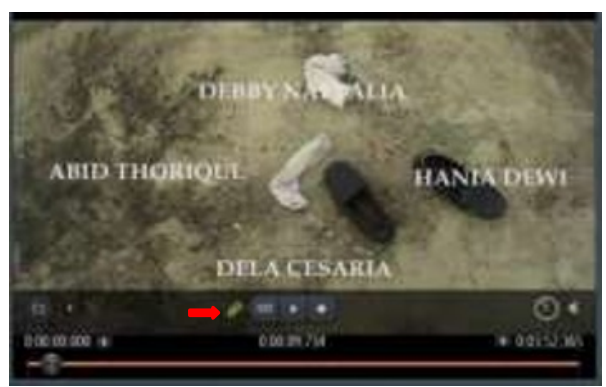

Fig. 2. Fruity video player playing the film.

For melodic instruments, a piano roll is used to compose tones that will be displayed throughout the scene [9]. The following Figure 3 shows the example of the piano instrument pattern made in a piano roll.

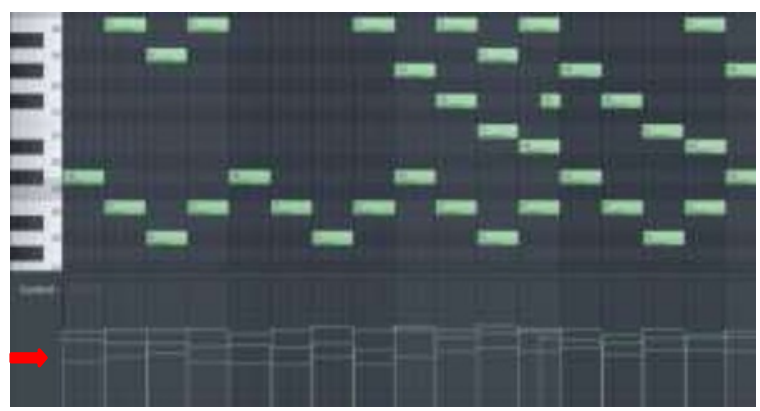

Fig. 3. Piano roll used to draw melodies and chords.

The red arrow shows how its velocity can adjust the arrangement of the tones. The settings on the velocity aim to give harmony to the instrument so that the various instruments do not stand out and overlap. Therefore, the velocity on each instrument needs to be adjusted so that the mixing of the music can be more harmonious. For non-pitched instruments, percussion is consists of instruments obtained from the orchestral library sample pack, which is recorded directly and then arranged in such a way as to fulfil our desires. There are crashes, low hits, cinematic drums, rolling toms, double hits, and deep impact sound effects. Figure 4 below shows percussion arrangements in aplaylist.

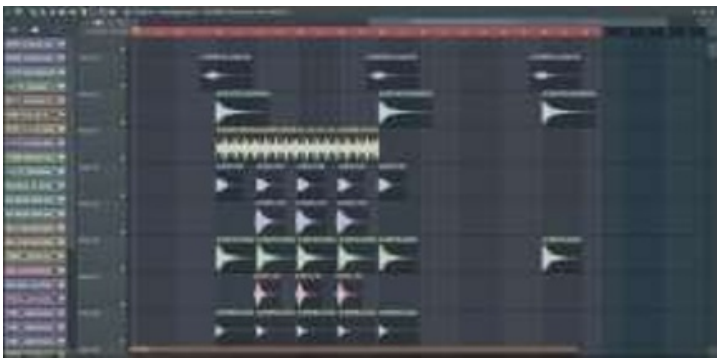

Fig. 4. Percussion is arranged in such a way as to form a rhythm to accomplish other instruments. 
After all the instrument patterns are complete, all patterns are arranged in a playlist regarding scenes in the film so that they can create an atmosphere in the film. The following Figure 5 shows all the instrument patterns that have been compiled to form new music.

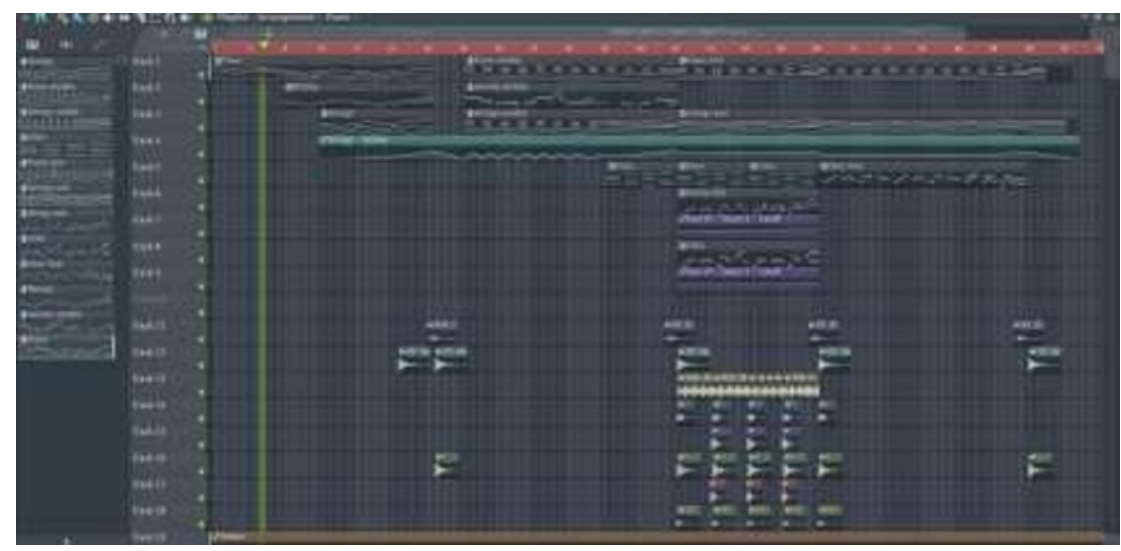

Fig. 5. Playlist; a place where tracks are united by dragging patterns that have been made to form musical unity [9].

\subsection{Audio mixing}

Audio mixing is the process of combining audio, MIDI and effects tracks into a pleasing form that makes use of such as the relative level, spatial positioning, equalization, and effects processing [10]. Figure 6 shows a mixer on FL Studio 20. The mixer feature is the main tool in audio mixing to control all instruments. After each instrument is arranged in a playlist, each track parameter in the playlist can be set using the mixer.

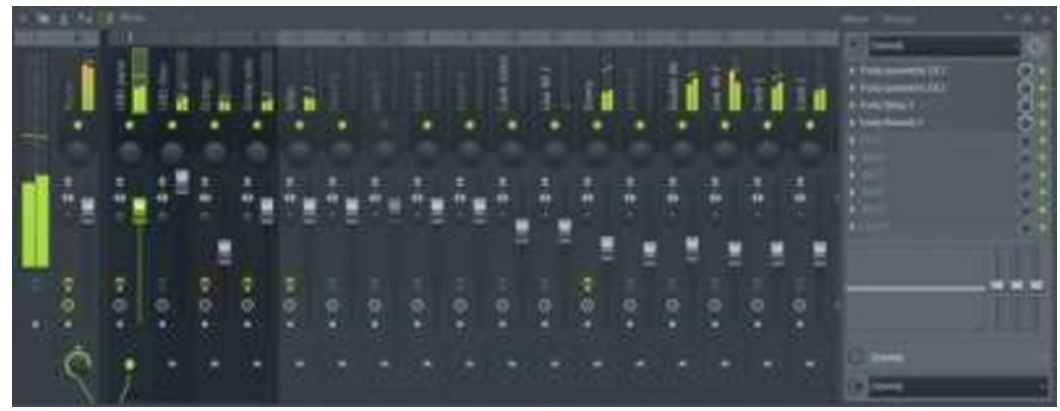

Fig. 6. Mixer controlling each track parameters.

On the right side of the mixer, there are slots of effect that you want to apply to each instrument such as equalizer settings, the addition of delay effects, and also the addition of reverb effects. Then it is about automation. Automation is one of the features in FL Studio that allows to make dynamic parameter changes automatically to the tracks of the selected instruments. Almost every setting in FL Studio can be made for automation such as volume, panning, cut-off instruments, et cetera. The trick is to right-click on the settings that want to be automated and then select Create Automation Clip. The following Figure 7 shows how to make an automation clip, and Figure 8 shows an example of putting it into playlist. 


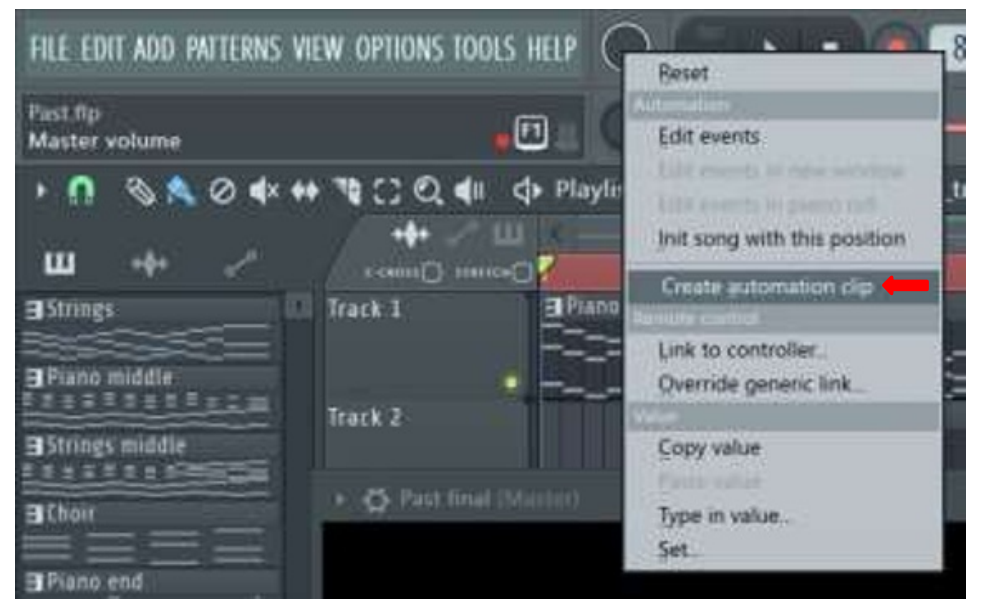

Fig. 7. Creating automation by right-clicking a parameter.

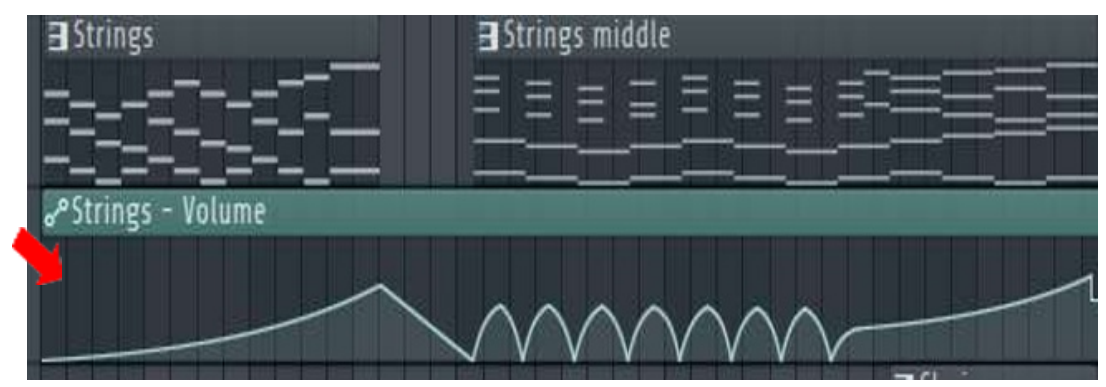

Fig. 8. Automation added on playlist.

\section{Result}

To find out the level of success of the music that has been made, testing is done on the audience through film screening. The audience was then given a questionnaire containing several parameters from making music for a film. Figure 9 shows the example results of respondent's answers to the music that has been made in this research.

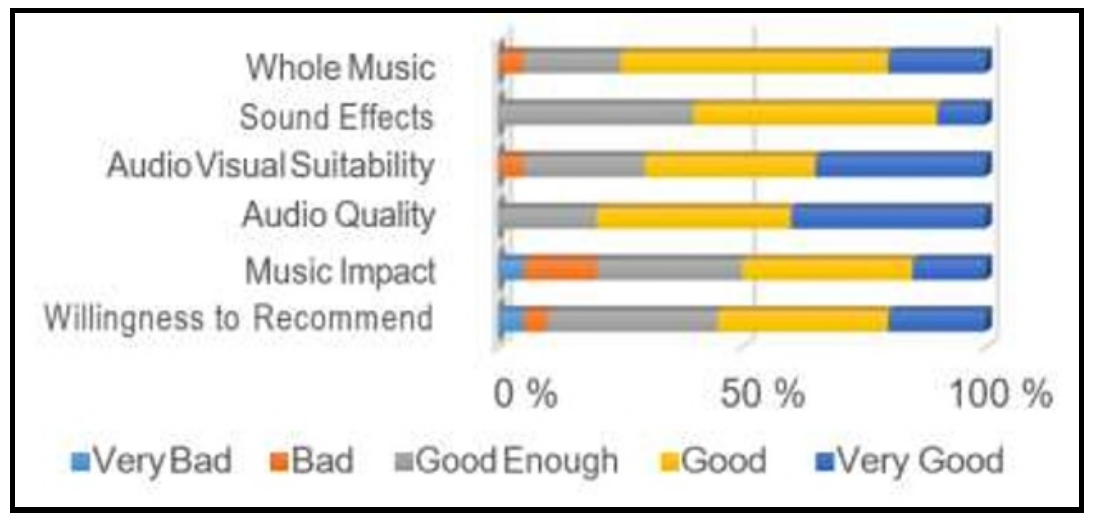

Fig. 9. Questionnaire result.

For overall of the music, the majority of the audience think that music in the film has successfully built the atmosphere of the film. For suggestions from respondents, audio is 
less able to increase the plot and characters' emotion, less detailed sound effects, and lack of suitability between audio and visual.

In the research of making music, it does not seem to have to run smoothly without any obstacles. This research conducted to make music takes a long time because the process of making music does not use additional hardware such as audio interfaces, MIDI controllers, and supporting speakers. In addition to the many variations of additional plugins from third parties also affect computer performance in running FL Studio software.

\section{Conclusion}

FL Studio is a DAW software that is right for music scoring. From the complete variety of features, affordable software price, and easy interface, even beginners can understand the world of making music very quickly. With some additional plugins from third parties, this study have been able to make music with the selected instruments. In making music for films, this study could use some additional supporting devices that are of high quality so that music production can run smoothly and quickly. The choice of monitor speakers also affects because the sound produced must be able to build the atmosphere of the film to the audience.

\section{References}

1. R. Minawati. Musikologi Jurnal Penciptaan dan Pengkajian 1,10:1-10(2018). [in Bahasa Indonesia] http://musikologi.uhn.ac.id/wp-content/uploads/2018/03/RostaMinawati-Musik-Pada-Film-Bukan-Sekedar-Latar.pdf

2. M. Evans. Music in films: Importance \& purpose. [online] from https://study.com/academy/lesson/music-in-films-importance-purpose.html (2017) [Accessed on 14 June 2020].

3. J. Drum. Tempo in music. [Online] from https://www.phoenixsymphony.org/ uploads/Tempo.pdf (2012). [Accessed on 2 January 2019]. [in Bahasa Indonesia].

4. R. Carreiro, L. Alvim. MATRIZes, 10,2:175-193(2016). [in Portuguese]. http://www.periodicos.usp.br/matrizes/article/view/120018

5. P.S. Flach. Film scoring today-theory, practice, and analysis. [Thesis] Departmen of Information Science and Media Studies, University of Bergen, Bergen (2012). p. 128. https://bora.uib.no/handle/1956/6016

6. C. Buskies, A.E. Scunio, M. Knauff, C. Adam. System and method to generate and manipulate string instrument chord grids in a digital audio workstation. [United States Patent] Canada, US: Apple Inc. (2014). https://patents.google.com/patent/US8759658B2/en

7. M. Pierce, G. Chiarenza. 5 Best DAWs: The complete guide to choosing your DAW. [Online] from https://equipboard.com/posts/best-daw (2016) [Accessed on 26 June 2019].

8. R. Suliza. Do you want to watch that movie? experimental study on the effects of music of movie trailers. [Thesis] Faculty of Behavioral Management and Social Sciences (BMS), University of Twente (2019). p. 45. https://essay.utwente.nl/77352/

9. A. Jones. The complete guide to FL studio 20. [online] from https://www.musictech.net/ tutorials/complete-guide-to-fl-studio-20/ (2018). [Accessed on 22 January 2019].

10. D.M. Huber, R.E. Runstein. Modern recording techniques. London: Focal Press (2010). p. 463. https://trove.nla.gov.au/work/8194508 